\title{
Kinetics of Zinc Evaporation from Aluminium Alloys Melted Using VIM and ISM Technologies
}

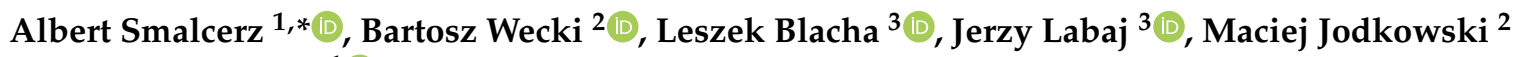 \\ and Adrian Smagor ${ }^{1}{ }^{\mathbb{B}}$
}

1 Department of Industrial Informatics, Faculty of Materials Science, Silesian University of Technology, Krasinskiego 8, 40-019 Katowice, Poland; adrian.smagor@polsl.pl

2 Department of Testing and Certification "ZETOM", Ks. Herberta Bednorza 17, 40-384 Katowice, Poland; bartosz.wecki@zetom.eu (B.W.); maciej.jodkowski@zetom.eu (M.J.)

3 Department of Metallurgy and Recycling, Faculty of Materials Science, Silesian University of Technology, Krasinskiego 8, 40-019 Katowice, Poland; leszek.blacha@polsl.pl (L.B.); jerzy.labaj@polsl.pl (J.L.)

* Correspondence: albert.smalcerz@polsl.pl; Tel.: +48-32-603-4133

Citation: Smalcerz, A.; Wecki, B.; Blacha, L.; Labaj, J.; Jodkowski, M.; Smagor, A. Kinetics of Zinc

Evaporation from Aluminium Alloys Melted Using VIM and ISM

Technologies. Materials 2021, 14, 6641. https://doi.org/10.3390/

ma14216641

Academic Editor: Frank Czerwinski

Received: 30 June 2021

Accepted: 26 October 2021

Published: 4 November 2021

Publisher's Note: MDPI stays neutral with regard to jurisdictional claims in published maps and institutional affiliations.

Copyright: (c) 2021 by the authors. Licensee MDPI, Basel, Switzerland. This article is an open access article distributed under the terms and conditions of the Creative Commons Attribution (CC BY) license (https:// creativecommons.org/licenses/by/ $4.0 /)$.

\begin{abstract}
Using a vacuum during the smelting and refining of alloys removes dissolved gasses, as well as impurities with high vapour pressure. When smelting is carried out in vacuum induction furnaces, the intensification of the discussed processes is achieved by intensive mixing of the bath, as well as an enhanced mass exchange surface (liquid metal surface) due to the formation of a meniscus. This is due to the electromagnetic field applied to the liquid metal. This study reports the removal of zinc from the Al-Zn alloy containing $6.3 \mathrm{wt} . \%$. Zn. The experiments were carried out with the use of two types of metallurgical devices: the VIM and ISM furnaces. For the experiments carried out in the crucible induction furnace, reduction in the operating pressure in the furnace from $1000 \mathrm{~Pa}$ to $10 \mathrm{~Pa}$, together with the increase in temperature from $953 \mathrm{~K}$ to $1103 \mathrm{~K}$, is accompanied by a decrease in zinc content in the alloy from 6 to $96 \%$, compared with the initial value. Simultaneously, the overall mass transfer coefficient $k_{\mathrm{Zn}}$ increases from $5.15 \times 10^{-6}$ to $-1.49 \times 10^{-4} \mathrm{~ms}^{-1}$. For the experiments carried out in the furnace with a cold crucible $(T=953 \mathrm{~K})$, a reduction in the operating pressure in the furnace from $1000 \mathrm{~Pa}$ to $10 \mathrm{~Pa}$ resulted in a decrease in zinc content in the alloy from 18 to $80 \%$, compared with the initial value. For comparison, the experiments carried out in the crucible induction furnace at $953 \mathrm{~K}$ showed a reduction in zinc content in the alloy from 6 to $50 \%$, which means that more intense zinc evaporation is seen in the furnace with a cold crucible. Comparison of ISM and VIM technologies in the removal efficiency of the Al-Zn alloy indicates a higher removal efficiency using the first technology, which, using the same conditions, achieves $80 \%$ of the removal efficiency of the component.
\end{abstract}

Keywords: vacuum refining of metals; vacuum induction melting (VIM); induction skull melting (ISM)

\section{Introduction}

The dynamic development of the world economy requires the supply of more and more materials that meet high-quality requirements. Metals belong to the group of strategic construction materials, but the basic issue of their use in advanced solutions is their purity. Physicochemical properties of metals, such as chemical affinity for oxygen, reductions, surface tension, viscosity, and gas vapour pressure, constitute basic barriers that, in the currently used refining technologies, are limitations for the level of removal of impurities in metals and their alloys. The emerging solutions based on scientific studies and the increasing technical possibilities of building advanced metallurgical structures create new possibilities, especially in the area of selective metal preparation and purification.

In the literature on the subject, one can find a well-documented database of results concerning metal refining processes with the use of melting aggregates based on inductive 
remelting under reduced pressure conditions, such as VIM. However, the emerging base of secondary raw materials and the exhausting existing resources of natural resources mean that the search for solutions that have the potential in the area of processing and selective recovery of materials with complex chemical compositions are particularly of interest. Such solutions include the induction skull melting (ISM) technology, which is based on induction melting using a phenomenon similar to levitation so that the melted metal does not come into contact with the crucible material, which can also often introduce contamination to the metal.

Due to the very high intensity of the interaction of electromagnetic forces, the liquid metal is affected by large forces that significantly increase the interface between the liquid and gas phases. Taking into account the kinetic analysis of metal refining processes, a considerable role in this process is played by the mass transfer surface, which is the interface.

The research results presented in this article constitute an innovative approach to the refining of metals, including zinc and aluminium. Thus far, due to high costs, ISM remelting solutions are used in the technologies of obtaining titanium, while the use of nonferrous metals in this technology requires a number of tests to supplement the knowledge in this field. Comparison of ISM and VIM technologies in the removal efficiency of the Al-Zn alloy indicates a higher removal efficiency using the first technology, which, using the same conditions, achieves $80 \%$ of the removal efficiency of the component.

The phenomenon of evaporation of volatile metal bath components can be observed in numerous processes of both extractive metallurgy and refining. In some of them, this phenomenon can be considered positive, while in others, however, to the contrary. In order to intensify the evaporation process or to restrain it, one must necessarily know the factors determining its rate. Among the most important of these factors are the pressure inside the system, the type of gas atmosphere, the temperature, and the hydrodynamic properties of the system in which the metallurgical process is carried out. Crucible-based vacuum induction furnaces (VIM technology), such as cold crucible induction furnaces (ISM technology), are melting machines used in modern refining or smelting processes. In these operations, due to the use of vacuum, it is possible to evaporate its components, characterised by high vapour pressure from the metallic bath.

The source of the electromagnetic field in induction furnaces is a coil made of copper. Taking into account the construction of crucible, we have two kinds of induction furnaces:

- Induction furnace with a non-conductive crucible, e.g., ceramic crucible;

- Induction furnace with a conductive crucible, e.g., graphite crucible or copper crucible in case of the cold crucible furnace.

Magnetic cores or magnetic field concentrators are applied to concentrate the electromagnetic field. Figure 1 shows a furnace in which the magnetic core is longer than the induction coil.

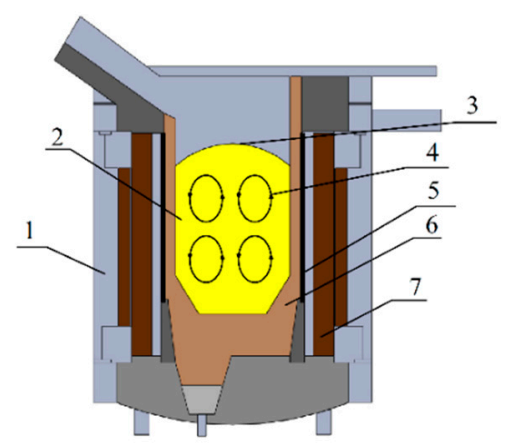

Figure 1. Scheme of the induction crucible furnace: 1-steel construction; 2-liquid metal; 3-meniscus; 4-mixing of metal; 5-inductor; 6-crucible; 7-ferromagnetic core [1]. 
The electromagnetic field generated by the alternating electric current flowing through the inductor, directly or indirectly, affects the workpiece placed inside the crucible. Eddy currents induced in the workpiece are responsible for heat generation in the metal. As a result of the interaction, the Lorentz force is generated [2-5]. It causes a convex meniscus of free surface and intensive stirring of the metal (Figure 1).

The application of direct heating in the crucible may cause intense reactions of the crucible with the metal, e.g., titanium or zircon [6]. It causes increased interest in indirect heating in cold crucible furnaces (Figure 2).

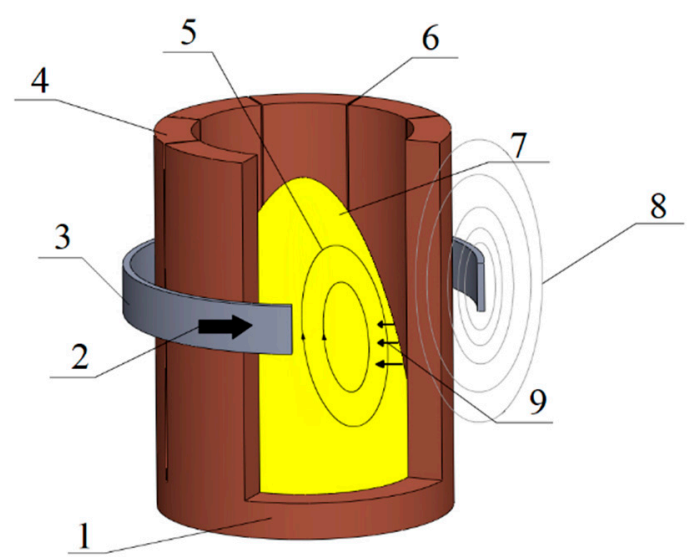

Figure 2. Scheme of the induction furnace with a cold crucible: 1-crucible; 2 -current; 3-inductor; 4—segment; 5-melt flow; 6-slit; 7—meniscus; 8-magnetic field; 9—force density [1].

Another technology for induction smelting, one that partially eliminates the disadvantages of classical crucible smelting, is smelting in induction furnaces with a so-called cold crucible (Figure 2).

The same phenomena occur in cold crucible furnaces (ISM technology). The watercooled crucible is mostly made of copper [7-11]. However, this means a limited transfer of energy to the workpiece. Eddy currents induced on the inner wall of the crucible are the source of the secondary electromagnetic field induced in the workpiece $[12,13]$.

When metals or their alloys are melted in induction furnaces (VIM or ISM), the surface area of the metal is strongly dependent on the electromagnetic field acting on the alloy and the properties of the liquid metal. This is evinced by the formation of a distinct meniscus on the surface of the bathtub. Increasing the surface of the liquid alloy can significantly intensify the discussed evaporation process.

The aims of this work include the following:

- Approximating the surface of liquid Al-Zn alloy melted using VIM and ISM technologies;

- $\quad$ Laboratory smelting of these alloys in variable pressure and temperature;

- Estimation of the overall mass transfer coefficient of zinc on the basis of experimental data;

- Determination of the stages in finding the velocity of the analysed evaporation process.

The selection of the alloy Al- $\mathrm{Zn}$ which the tests were conducted resulted from the fact that zinc as a component of this alloy is characterised by much higher vapour pressure, compared with aluminium. The paper presents the kinetic analysis of zinc evaporation from the Al-Zn alloy containing $6.3 \mathrm{wt} . \%$. Zn. The experiments were carried out with the use of two types of metallurgical devices - the VIM and ISM furnaces, ranging from $953 \mathrm{~K}$ to $1103 \mathrm{~K}$ and a wide range of operating pressures, from $10 \mathrm{~Pa}$ to $1000 \mathrm{~Pa}$. 


\section{Materials and Methods}

\subsection{A Thermodynamic Condition of Zinc Evaporation from Liquid Aluminium}

The potential for evaporation of the A element from a two-component A-B alloy is determined by the evaporation coefficient $\Omega$ which is described by the equation [14].

$$
\Omega=\frac{\gamma_{A} \cdot P_{A}^{0}}{\gamma_{B} \cdot P_{B}^{0}}
$$

where $P_{A}{ }^{0}, P_{B}{ }^{0}$ - equilibrium vapour pressures over pure components $A$ and $B$, respectively; $\gamma_{A}, \gamma_{B}$-coefficients of activity in the alloy for $A$ and $B$, respectively.

For the two-component $A-B$ alloy, with $\Omega \approx 1$, it is assumed that the chemical composition of the alloy does not change during the smelting process. When the coefficient value is $\Omega>1$, we can infer a loss (evaporation) of the $A$ component from the alloy relative to the $B$ component. When the following condition is met: $\Omega<1$, we can infer a loss (evaporation) of the $B$ component from the alloy.

According to Oletta [15], the value describing the potential for evaporation of a liquid component from a metallic alloy is the so-called volatility ratio. In the case of a twocomponent alloy with an atomic metal vapor system, the volatility ratio is defined by the following equation:

$$
\Phi_{B}=\left(\gamma_{B} \frac{p_{B}^{0}}{p_{A}^{0}}\right) \cdot\left(\frac{M_{A}}{M_{B}}\right)^{0,5}
$$

where $\Phi_{B}$-volatility ratio of the alloy $B$ component; $M_{A}, M_{B}$-atomic (molar) mass of the alloy main component $A$ and the evaporating component $B$.

It is generally assumed that the process of ' $i$ ' component evaporation is possible if the following condition is met:

$$
\Phi_{\mathrm{i}}>1
$$

Metal can evaporate in both atomic and particulate forms. In the latter case, the volatility ratio equation takes the following form:

$$
\Phi_{B}=\left(\frac{M_{A}}{M_{B}}\right)^{0,5} \cdot\left(\frac{p_{B}^{0}}{p_{A}^{0}}\right) \cdot \gamma_{B} \cdot X_{B}^{(j-1)},
$$

where $X_{B}$-a molar fraction of the $B$ component of the alloy; $j$-the number of atoms in the metal particle $B$ in the gaseous phase.

Figure 3 presents a change of the $\Omega$ ratio for the Al-Zn alloy ( $6.3 \mathrm{wt} . \% \mathrm{Zn})$ within the temperature range of $953-1103 \mathrm{~K}$. A similar relation describing the $\Phi$ volatility ratio for the same alloy is presented in Figure 4.

The data presented in Figures 3 and 4 indicate that, from the thermodynamics point of view, there is a possibility to evaporate Zinc from the investigated Al-Zn alloy within the assumed temperature range. For the studied alloy, both $\Omega_{\mathrm{Zn} / \mathrm{Al}}$ and $\Phi_{\mathrm{Zn}}$ ratios are $>1$. The values of the volatility and evaporation ratios presented in Figures 3 and 4 were determined based on the thermodynamics data taken from a study by Plewa [16] and the HSC Chemistry Database [17]. 


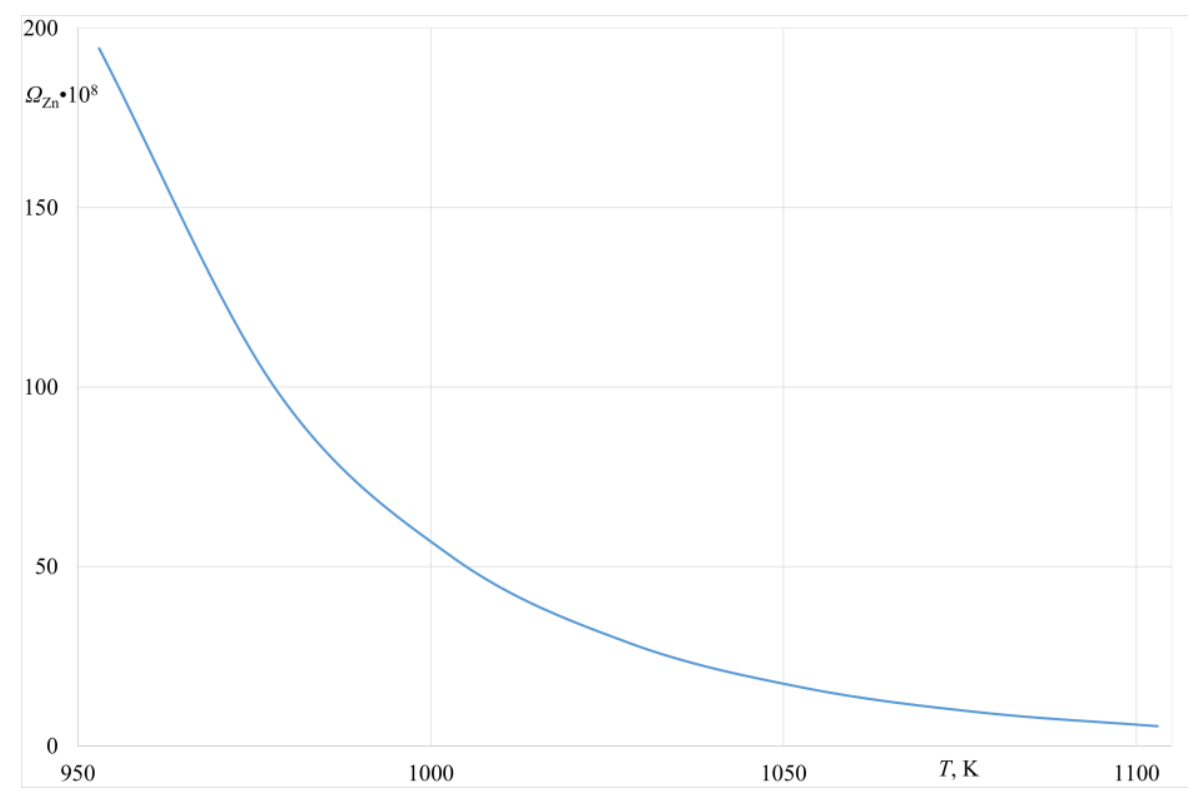

Figure 3. $\Omega$ ratio for the Al-Zn alloy $(6.3 \% \mathrm{wt} . \% \mathrm{Zn})$.

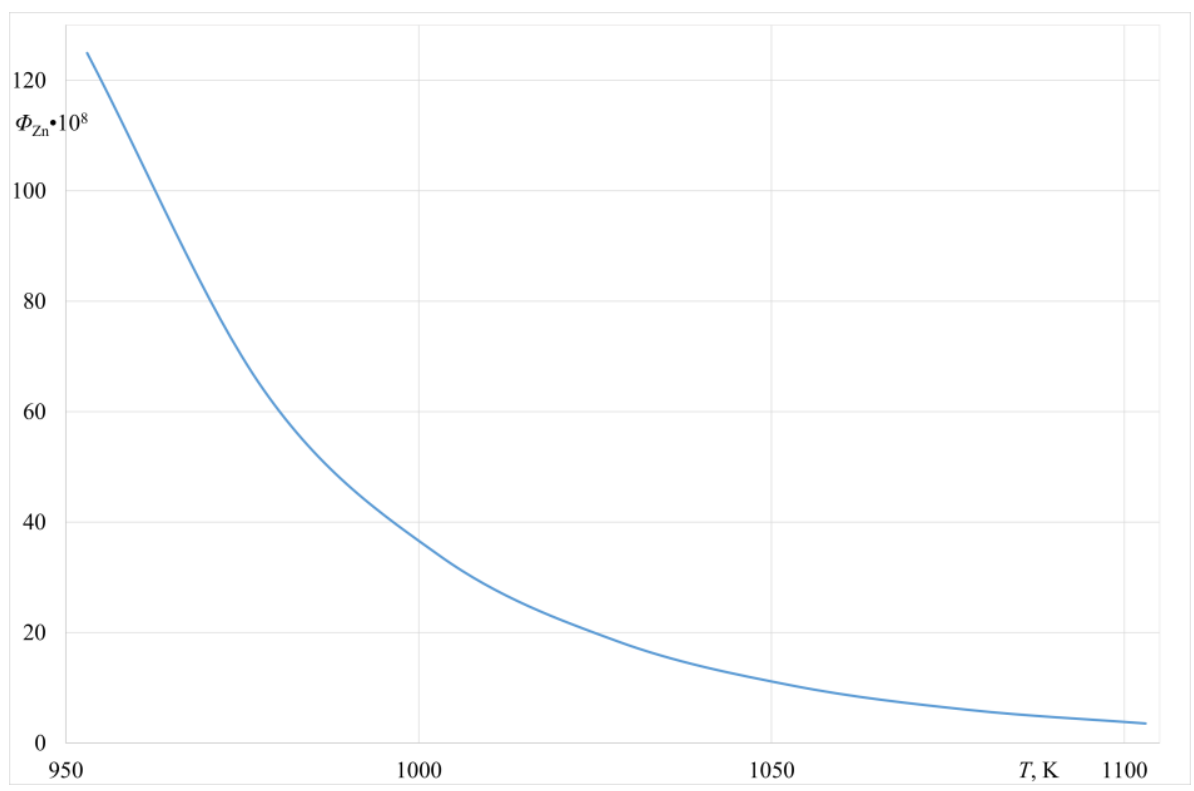

Figure 4. $\Phi$ volatility ratio for the Al-Zn alloy (6.3\% wt. $\% \mathrm{Zn})$.

\subsection{Experimental Procedures}

The research experiments were performed on a multi-component $\mathrm{Al}-\mathrm{Zn} 5.5 \mathrm{MgCu}$ alloy; its composition is presented in Table 1.

Table 1. Chemical composition of the investigated alloy.

\begin{tabular}{cccccccccc}
\hline \multicolumn{10}{c}{ Content of Basic Alloy Components. wt.\% } \\
\hline $\mathrm{Zn}$ & $\mathrm{Mg}$ & $\mathrm{Cu}$ & $\mathrm{Mn}$ & $\mathrm{Fe}$ & $\mathrm{Si}$ & $\mathrm{Cr}$ & $\mathrm{Ti}$ & $\mathrm{Zr}$ & $\mathrm{Al}$ \\
6.3 & 2.5 & 1.6 & 0.3 & $<0.5$ & $<0.4$ & 0.23 & $<0.05$ & 0.01 & residue \\
\hline
\end{tabular}

The melting furnaces applied in the experiments were the VIM-20 vacuum induction melting furnace and the vacuum furnace with a cold crucible ISM 2-200 (Seco-Warwick, Swiebodzin, Poland). 
All the experiments assumed in the research were conducted following a fixed scheme. In the first stage, when the sample was placed in the furnace, the pressure was lowered in the working chamber, and then the charge was heated and melted. Upon reaching the set temperature by the liquid metal, it was maintained in the furnace for $600 \mathrm{~s}$. The temperature measurement was performed using a thermoelectric B-type sensor PtRh30-PtRh6 and an optical pyrometer (PI 1M, Optris, Germany). During the process, a sample of liquid metal was collected at defined intervals. When the experiment finished, the chemical composition of the metal was analysed. For this purpose, the atomic absorption spectrometry method with the ASA solar device was used.

In the VIM unit, the process was performed within the temperature range of $953 \mathrm{~K}$ to $1103 \mathrm{~K}$, while the ISM unit experiments were conducted at $953 \mathrm{~K}$. The recorded changes in the furnace operating power ranged from $8 \mathrm{~kW}$ to $22 \mathrm{~kW}$ and from $70 \mathrm{~kW}$ to $130 \mathrm{~kW}$ for the VIM furnace and the ISM furnace, respectively. The operating pressure in both units was changed within the range of $10 \mathrm{~Pa}$ to $1000 \mathrm{~Pa}$.

\section{Results}

Results obtained in all experiments are presented in Tables 2 and 3. In addition to the basic parameters of each experiment, the final $\mathrm{Zn}$ content in the alloy and its removal fraction $\left(U_{Z n}\right)$ are shown. Graphic interpretations of these results are shown in Figures 5 and 6.

Table 2. Results of the experiments performed in the crucible induction furnace (VIM).

\begin{tabular}{ccccc}
\hline No. & $\mathbf{T}, \mathbf{K}$ & $\boldsymbol{p}, \mathbf{P a}$ & Final Zinc Concentration, wt. $\%$ & $\boldsymbol{U}_{\mathbf{Z n} \boldsymbol{n}, \boldsymbol{\%}}$ \\
\hline 1 & 953 & 1000 & 5.91 & 6.19 \\
2 & 953 & 500 & 5.37 & 14.76 \\
3 & 953 & 100 & 5.00 & 20.63 \\
4 & 953 & 10 & 3.16 & 49.84 \\
5 & 1013 & 1000 & 5.46 & 13.33 \\
6 & 1013 & 500 & 5.18 & 17.77 \\
7 & 1013 & 100 & 4.46 & 29.20 \\
8 & 1013 & 10 & 2.54 & 59.68 \\
9 & 1073 & 1000 & 3.71 & 41.11 \\
10 & 1073 & 500 & 3.28 & 47.93 \\
11 & 1073 & 100 & 2.55 & 59.52 \\
12 & 1073 & 10 & 2.21 & 64.92 \\
13 & 1103 & 1000 & 1.45 & 76.98 \\
14 & 1103 & 500 & 1.23 & 80.47 \\
15 & 1103 & 100 & 0.89 & 85.87 \\
16 & 1103 & 10 & 0.25 & 96.03 \\
\hline
\end{tabular}

Table 3. Results of the experiments performed in the induction furnace with a cold crucible.

\begin{tabular}{cccccc}
\hline No. & $\mathbf{T , K}$ & $\boldsymbol{p}, \mathbf{P a}$ & Operating Power, $\mathbf{k W}$ & Final Zinc Concentration, wt. $\%$ & $\boldsymbol{U}_{\mathbf{Z n}}, \boldsymbol{\%}$ \\
\hline 1 & 953 & 1000 & 70 & 5.13 & 18.57 \\
2 & 953 & 500 & 70 & 4.89 & 22.38 \\
3 & 953 & 100 & 70 & 4.26 & 32.38 \\
4 & 953 & 10 & 70 & 2.37 & 62.38 \\
5 & 953 & 1000 & 100 & 3.78 & 40.01 \\
6 & 953 & 500 & 100 & 3.51 & 44.28 \\
7 & 953 & 100 & 100 & 3.03 & 51.90 \\
8 & 953 & 10 & 100 & 1.48 & 76.50 \\
9 & 953 & 1000 & 130 & 3.56 & 43.49 \\
10 & 953 & 500 & 130 & 3.22 & 48.88 \\
11 & 953 & 100 & 130 & 2.81 & 55.39 \\
12 & 953 & 10 & 130 & 1.31 & 79.20 \\
\hline
\end{tabular}




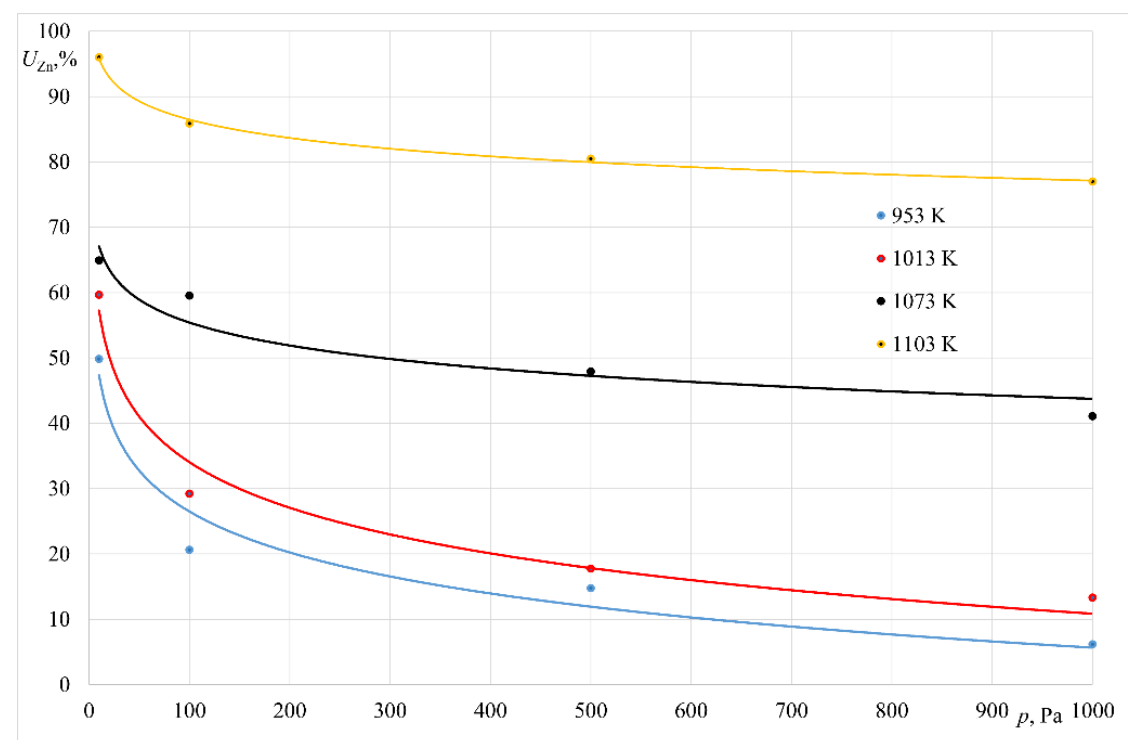

Figure 5. Relative zinc mass loss for the experiments performed in the crucible furnace.

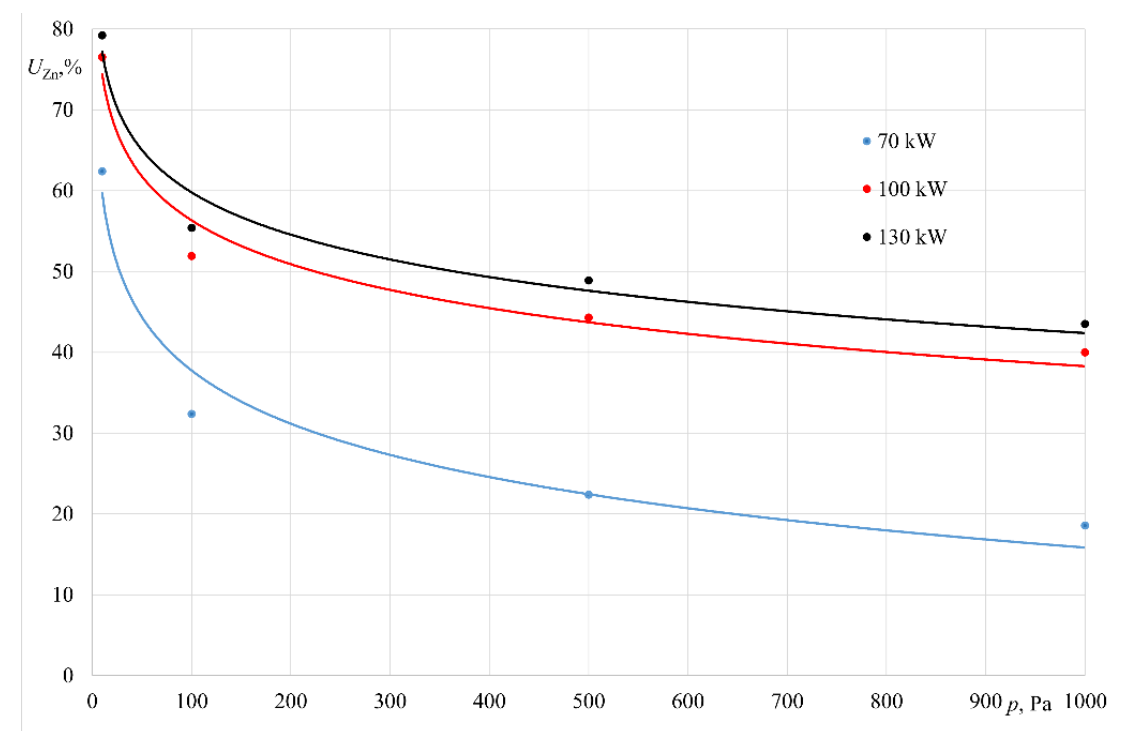

Figure 6. Relative zinc mass loss for the experiments performed in the furnace with a cold crucible.

As indicated by the data presented in Table 2, a raise in the process temperature from $953 \mathrm{~K}$ to $1103 \mathrm{~K}$, with a simultaneous reduction in the operating pressure in the vacuum crucible furnace results in an increase in the relative Zinc loss in the alloy from $6.19 \%$ to $96.03 \%$.

For the experiments conducted at $935 \mathrm{~K}$, the loss of zinc mass was as follows, depending on the unit applied: $6.19 \%$ to $49.84 \%$ for the experiments conducted in the crucible furnace; $18.57 \%$ to $79.20 \%$ for the experiments conducted in the furnace with a cold crucible.

\section{Discussion}

The elimination of impurities in vacuum induction melting is generally observed to follow first-order kinetics [18]. As a result, the overall Zinc elimination rate can be described by the following equation:

$$
\frac{d C_{Z n}}{d t}=k_{Z n} \cdot \frac{F}{V} \cdot C_{Z n}
$$


This relationship can be written in the following integral form:

$$
\int_{0}^{t} \frac{d C_{Z n}}{C_{Z n}}=k_{Z n} \cdot \frac{F}{V} \int_{0}^{t} d t
$$

After integrating Equation (6), we have:

$$
2.303 \log \frac{C_{Z n}^{t}}{C_{Z n}^{0}}=-k_{Z n} \frac{F}{V}\left(t-t_{0}\right),
$$

where $C_{Z n}{ }^{0}, C_{Z n}{ }^{t}$-zinc concentrations in the alloy, initial and at $t$, respectively (wt.\%); $k_{Z n}$-overall mass transfer coefficient $\left(\mathrm{ms}^{-1}\right) ; F$-evaporation surface area $\left(\mathrm{m}^{2}\right) ; V$-liquid metal volume $\left(\mathrm{m}^{3}\right) ;\left(t-t_{0}\right)$-duration of the process (s).

The form of Equation (7) shows that in order to determine the value of the $k_{\mathrm{Zn}}$ coefficient, it is necessary to know the volume of the melt and its surface. In the analysed experiments, within $953 \mathrm{~K}$ to $1103 \mathrm{~K}$, the estimated value of the liquid metal volume fell within the range of 420 to $425 \mathrm{~cm}^{3}$. The values of liquid aluminium density within the analysed temperature range were determined based on the data in $[19,20]$. They ranged from 2.37 to $2.41 \mathrm{~g} \mathrm{~cm}^{-3}$.

When analysing the process of zinc evaporation from molten aluminium alloys during their smelting in a vacuum induction furnace, attention should be paid to the issue of increasing the liquid metal surface with the increase in power released in the charge. With greater power, we observe a significant increase in the bath surface due to the formation of a meniscus, which is an effect of the electromagnetic field acting on the liquid metal.

To estimate the size of the surface, the following method of determining the area consisting of four stages was proposed [1]:

- Acquisition of images of the molten metal with the use of a high-speed camera;

- Determination of the resulting meniscus geometry on the basis of the obtained photos;

- Determination of the functions of the curves describing the meniscus for various process parameters;

- Estimation of the surface area using the programs Wolfram Mathematica (F1).

As part of the first stage, using a Phantom v5.1 camera and the FLIR thermal imaging camera, a series of photos of the liquid metal was taken during the process for the assumed operating parameters of the furnace. The use of the WebPlotDigitizer 4.1 program allowed us to place points on the photos describing the resulting geometry. Based on this, a line and a function describing the shape of the interface were determined. Figure 7 shows an exemplary photo of liquid aluminium melted in the ISM furnace.

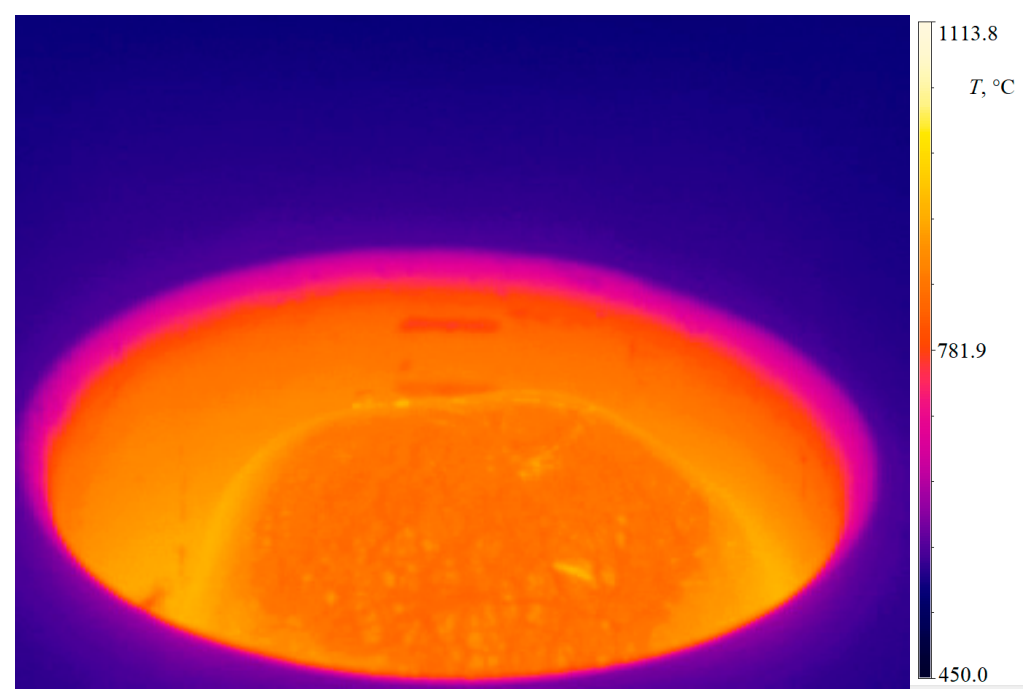

Figure 7. Images of the surface of aluminium melted in the ISM furnace. 
Table 4 summarises the values of the meniscus surface area estimated for all experiments using the proposed calculation method.

Table 4. Values of the surface area of meniscus formed for Al-Zn alloys, estimated with the use of the proposed calculation method.

\begin{tabular}{cccc}
\hline No. & $\boldsymbol{p}, \mathbf{k W}$ & Furnace & $\mathbf{F}, \mathbf{c m}^{\mathbf{2}}$ \\
\hline 1 & 8 & VIM & 88.1 \\
2 & 12 & VIM & 92.4 \\
3 & 17 & VIM & 108.7 \\
4 & 22 & VIM & 155.0 \\
5 & 70 & ISM & 280.0 \\
6 & 100 & ISM & 311.8 \\
7 & 130 & ISM & 330.3 \\
8 & 8 & VIM & 88.1 \\
12 & 12 & VIM & 92.4 \\
\hline
\end{tabular}

The values of the zinc overall mass transfer coefficient $k_{Z n}$, determined based on Equation (7), are presented in Tables 5 and 6 . Figures 8 and 9 show a graphic interpretation of changes in the coefficient $k_{Z n}$ values versus the operating pressure of the crucible induction furnace.

Table 5. The overall mass transfer coefficient $k_{Z n}$ as well as the coefficients $\beta_{Z n}^{l}$ and $k_{Z n}^{\mathrm{e}}$ (crucible induction furnace).

\begin{tabular}{|c|c|c|c|c|}
\hline$T, \mathrm{~K}$ & $p, \mathrm{~Pa}$ & $k_{Z n}, \mathrm{~m} \mathrm{~s}^{-1}$ & $\beta_{Z n}^{l}, \mathrm{~m} \mathrm{~s}^{-1}$ & $k_{Z n}^{\mathrm{e}}, \mathrm{m} \mathrm{s}^{-1}$ \\
\hline 5953 & 1000 & 0.00000515 & 0.000549 & 0.000324 \\
\hline 953 & 500 & 0.0000129 & 0.000549 & 0.000324 \\
\hline 953 & 100 & 0.0000185 & 0.000549 & 0.000324 \\
\hline 953 & 10 & 0.0000556 & 0.000549 & 0.000324 \\
\hline 1013 & 1000 & 0.0000109 & 0.000542 & 0.00036 \\
\hline 1013 & 500 & 0.0000149 & 0.000542 & 0.00036 \\
\hline 1013 & 100 & 0.0000264 & 0.000542 & 0.00036 \\
\hline 1013 & 10 & 0.0000696 & 0.000542 & 0.00036 \\
\hline 1073 & 1000 & 0.0000351 & 0.00052 & 0.000425 \\
\hline 1073 & 500 & 0.0000426 & 0.00052 & 0.000425 \\
\hline 1073 & 100 & 0.0000592 & 0.00052 & 0.000425 \\
\hline 1073 & 10 & 0.0000685 & 0.00052 & 0.000425 \\
\hline 1103 & 1000 & 0.0000673 & 0.000478 & 0.000531 \\
\hline 1103 & 500 & 0.0000748 & 0.000478 & 0.000531 \\
\hline 1103 & 100 & 0.0000896 & 0.000478 & 0.000531 \\
\hline 1103 & 10 & 0.000149 & 0.000478 & 0.000531 \\
\hline
\end{tabular}

The data in Tables 5 and 6 show that the reduction in the operating pressure of the furnace working chamber from $1000 \mathrm{~Pa}$ to $10 \mathrm{~Pa}$ results in an increase in the overall mass transfer coefficient $k_{Z n}$. This refers to the experiments carried out in both the crucible induction furnace and the induction furnace with a cold crucible. The values of the $k_{Z n}$ coefficient obtained in the research are fairly consistent with the literature data reported by other authors studying the process of zinc evaporation from copper, iron, and aluminium alloys melted in the conditions of lower pressure [21-24]. For the furnace with a cold crucible, the increase in the operating power from $70 \mathrm{~kW}$ to $130 \mathrm{~kW}$ results in a higher overall mass transfer coefficient $k_{Z n}$ due to an intensified process of liquid alloy stirring, with a higher furnace power. 
Table 6. The overall mass transfer coefficient $k_{Z n}$ and the coefficients $\beta_{Z n}^{l}$ and $k^{\mathrm{e}} \mathrm{Zn}$ (induction furnace with a cold crucible).

\begin{tabular}{cccccc}
\hline $\mathbf{T}, \mathbf{K}$ & $\boldsymbol{p}, \mathbf{P a}$ & $\boldsymbol{p}, \mathbf{k W}$ & $k_{Z n}, \mathbf{m ~ s}^{-\mathbf{1}}$ & $\boldsymbol{\beta}_{\mathbf{Z n}, \mathbf{m ~ s}}^{\mathbf{l}}$ & $\boldsymbol{k}_{\mathbf{Z}}^{\mathbf{e}}, \mathbf{m ~ s}^{-\mathbf{1}}$ \\
\hline 953 & 1000 & 70 & 0.00000517 & 0.0004 & 0.000324 \\
953 & 500 & 70 & 0.00000636 & 0.0004 & 0.000324 \\
953 & 100 & 70 & 0.000009768 & 0.0004 & 0.000324 \\
953 & 10 & 70 & 0.00002444 & 0.0004 & 0.000324 \\
953 & 1000 & 100 & 0.00001151 & 0.00039 & 0.000324 \\
953 & 500 & 100 & 0.00001316 & 0.00039 & 0.000324 \\
953 & 100 & 100 & 0.00001646 & 0.00039 & 0.000324 \\
953 & 10 & 100 & 0.00003268 & 0.00039 & 0.000324 \\
953 & 1000 & 130 & 0.00001213 & 0.00038 & 0.000324 \\
953 & 500 & 130 & 0.00001423 & 0.00038 & 0.000324 \\
953 & 100 & 130 & 0.00001714 & 0.00038 & 0.000324 \\
953 & 10 & 130 & 0.0000334 & 0.00038 & 0.000324 \\
\hline
\end{tabular}

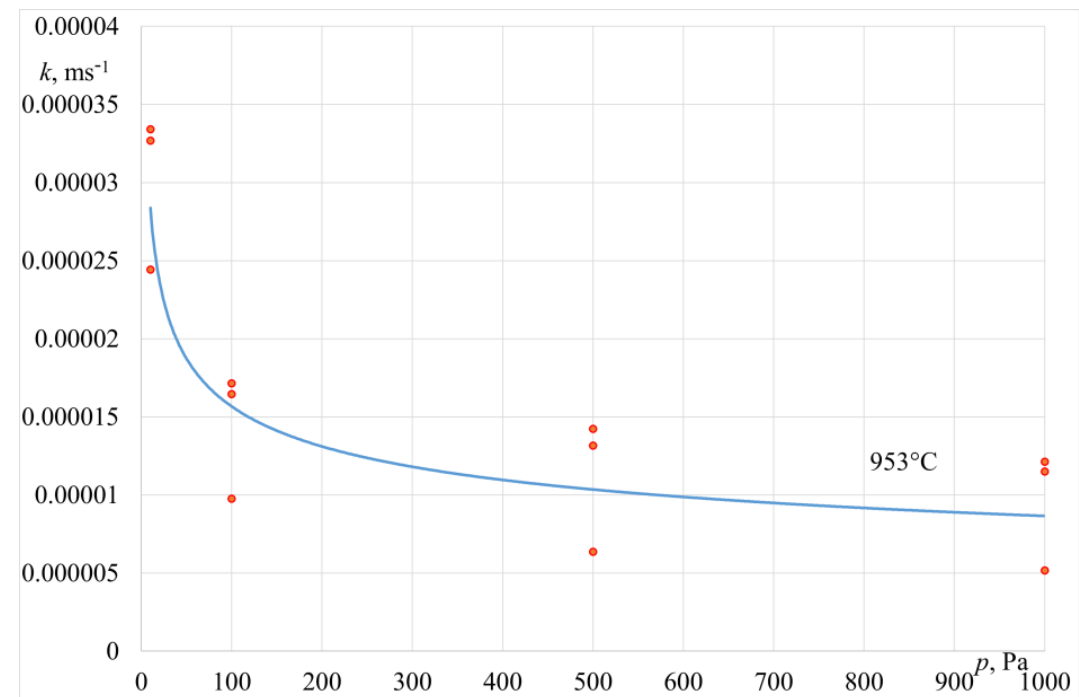

Figure 8. Variation of overall mass transfer coefficient $k_{Z n}$ vs. pressure (crucible induction furnace).

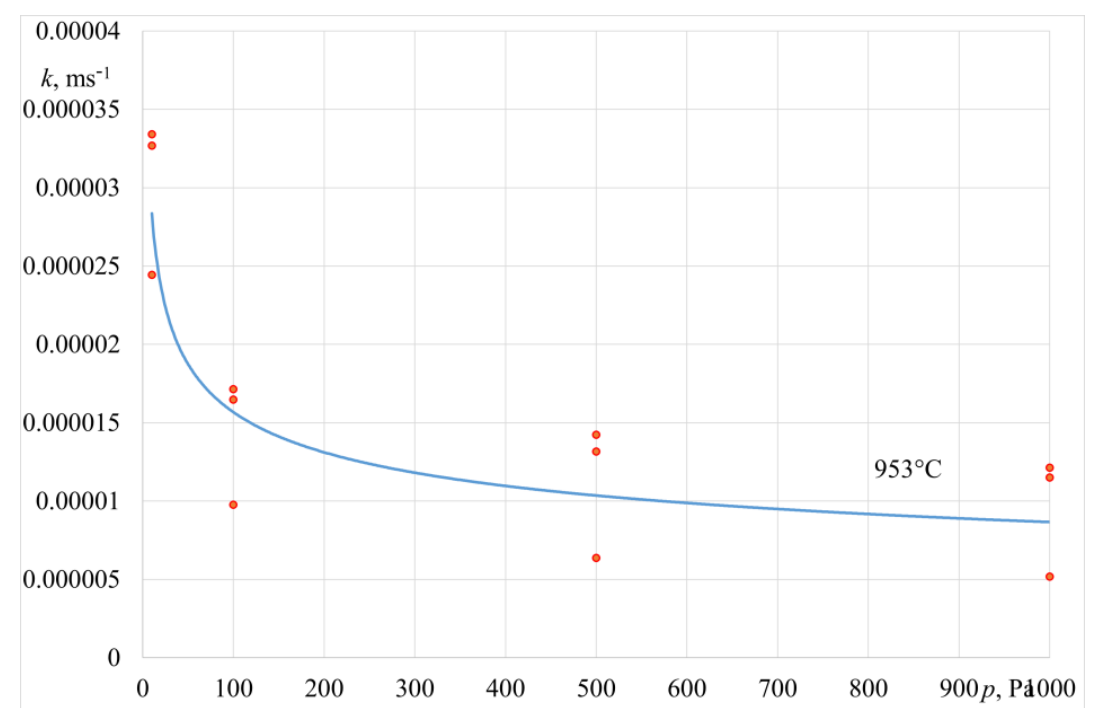

Figure 9. Variation of overall mass transfer coefficient $k_{Z n}$ vs. pressure (induction furnace with a cold crucible). 


\subsection{Mass Transfer in the Liquid Phase}

For a metal which is melted and stirred in the induction furnace, the arsenic mass transfer coefficient $\beta^{l}$ can be determined with the use of the recommended Machlin's equation [25] as follows:

$$
\beta^{l}=\left(\frac{8 D_{\mathrm{Zn}} \vartheta_{m}}{\pi r_{m}}\right),
$$

where $v_{m}$-near-surface velocity of inductively stirred liquid metal; $r_{m}$-radius of the liquid metal surface (most commonly assumed to be the crucible inner radius); $D_{\mathrm{Zn}}-\mathrm{Zn}$ diffusion coefficient in liquid aluminium.

By analogy to penetration models of mass transfer, Machlin assumed that liquid metal components move along the tangent, i.e., liquid metal-gas or liquid metal-crucible, and the velocity gradient normal to the surface is near the zero value. The equation shows that the $\beta^{l}$ value is directly proportional to the near-surface velocity of the liquid metal. Most of the authors who study the evaporation kinetics of inductively stirred metal bath components assumed consistently with Machlin that this velocity is practically independent of the electrical parameters of furnace operation. For induction furnaces with a capacity of up to $1 \mathrm{Mg}$, the value of $v_{m}$ was assumed to be constant and equal to $0.1 \mathrm{~ms}^{-1}$. However, further studies showed that this velocity depends on parameters such as the furnace power, current frequency, crucible geometry, or the crucible location in the furnace relative to the inductor $[26,27]$. In the present paper, the $\beta^{l}$ coefficient was determined using the near-surface velocity data from studies by $[28,29]$, in which they were estimated for various metal alloys in experiments carried out in the same melting device [30].

Tables 5 and 6 present values of the $\beta^{l}$ coefficient determined based on Equation (8). They fell within the range of the analysed temperatures and ranged from 3.8 to $5.4910^{-4} \mathrm{~ms}^{-1}$. The value of the zinc diffusion coefficient in liquid aluminium was estimated based on the data contained in the paper [31].

Figures 10 and 11 present the estimated transfer resistance in the liquid phase as a fraction of the overall resistance of zinc evaporation for processes carried out at $1003 \mathrm{~K}$ and $1103 \mathrm{~K}$. The following equation was applied:

$$
R^{l}=\frac{\left(\frac{1}{\beta^{l}}\right)}{\left(\frac{1}{k_{Z n}}\right)} \cdot 100 \%,
$$

The data in Figures 10 and 11 indicate that for the temperature and pressure ranges in the analysed experiments, zinc evaporation is not determined by mass transfer in the liquid phase. Mass transfer resistance in the liquid metal phase as a fraction of the overall process resistance does not exceed 31\%. The pressure decrease is associated with a slightly increased fraction of this resistance. This refers to the experiments conducted in both melting devices. 


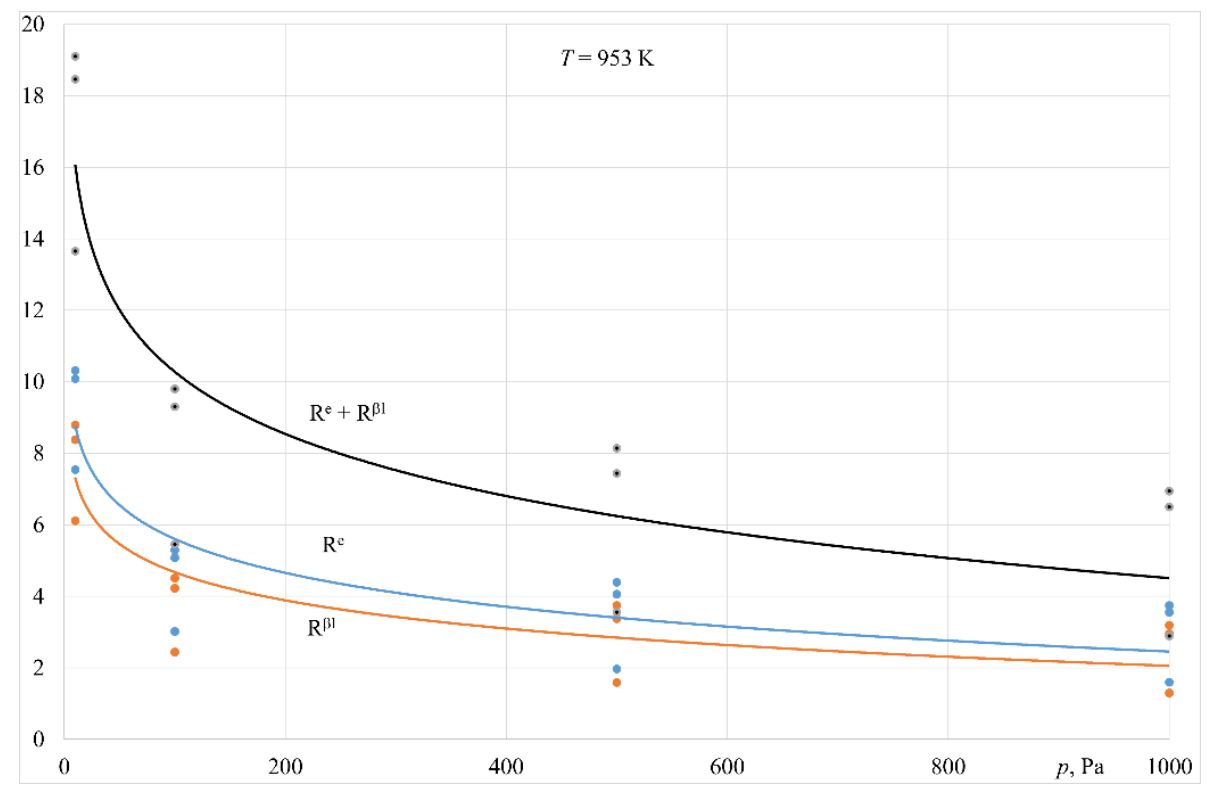

Figure 10. Variation in the resistance of mass transfer in the liquid phase $\left(R^{\beta l}\right)$ and reaction on the surface of the liquid metal $\left(R^{e}\right)$ in overall resistance of evaporation process vs. pressure (crucible induction furnace).

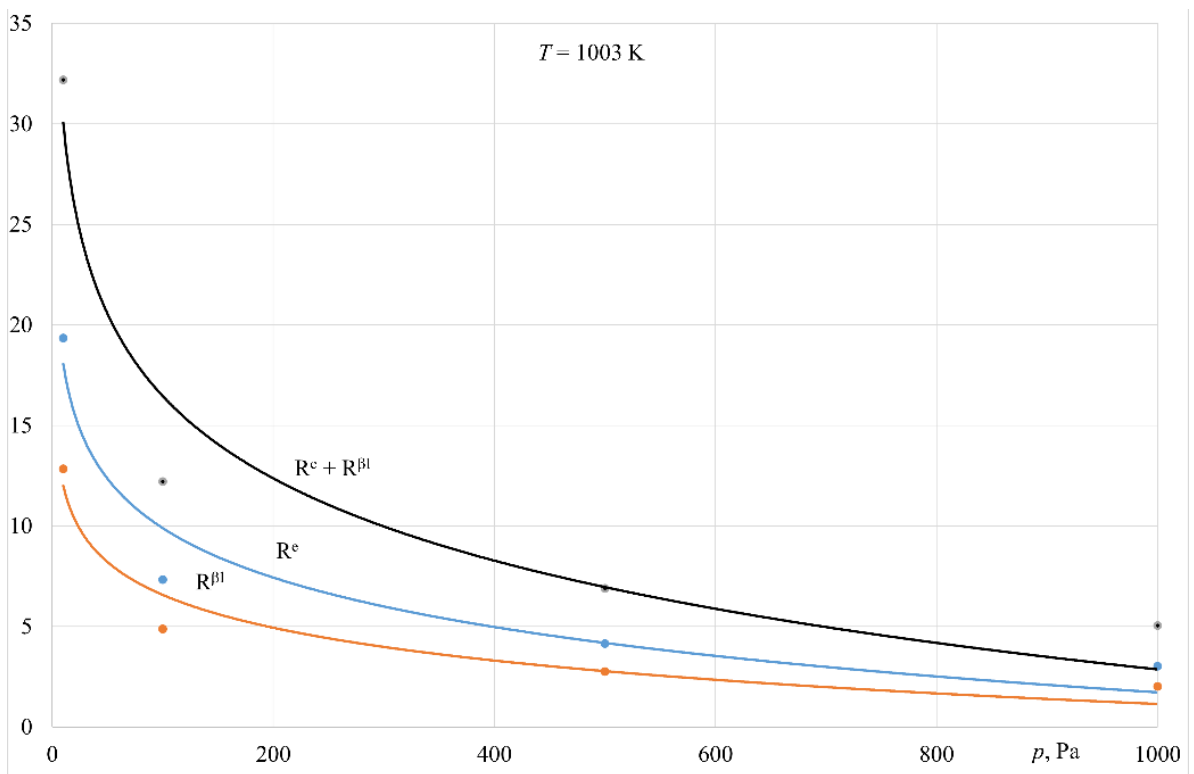

Figure 11. Variation in the resistance of mass transfer in the liquid phase $\left(R^{\beta l}\right)$ and reaction on the surface of the liquid metal $\left(R^{e}\right)$ in overall resistance of evaporation process vs. pressure (induction furnace with a cold crucible).

\subsection{Evaporation from the Surface}

When analysing the rate of zinc evaporation from the liquid alloy surface, the maximum value of rate constant $k^{e} \mathrm{Zn}$ was assumed to be described by the following equation:

$$
k_{Z n}^{e}=\frac{\alpha \cdot p_{Z n}^{0} \gamma_{Z n} \cdot M_{A l}}{\left(2 \pi R T M_{Z n}\right)^{0,5} \cdot \rho_{A l}},
$$

where $\alpha$-evaporation constant; $p^{0} \mathrm{Zn}$-equilibrium vapour pressure of zinc over liquid metal; $\gamma_{Z n}$-activity coefficient of zinc in liquid aluminium; $M_{A l}, M_{Z n}$ - the molar mass of aluminium and zinc, respectively; $\rho_{A l}$-aluminium density. In the present paper, the 
values of zinc vapour pressures $p^{0} \mathrm{Zn}$ were determined based on the data from the HSC thermodynamic database [17], and the values of the activity coefficient for zinc in liquid aluminium $\gamma_{Z n}$ were determined based on the data reported in a study by [16]. The estimated values of $k^{e} \mathrm{Zn}$ are summarised in Tables 5 and 6 and presented graphically in Figure 12.

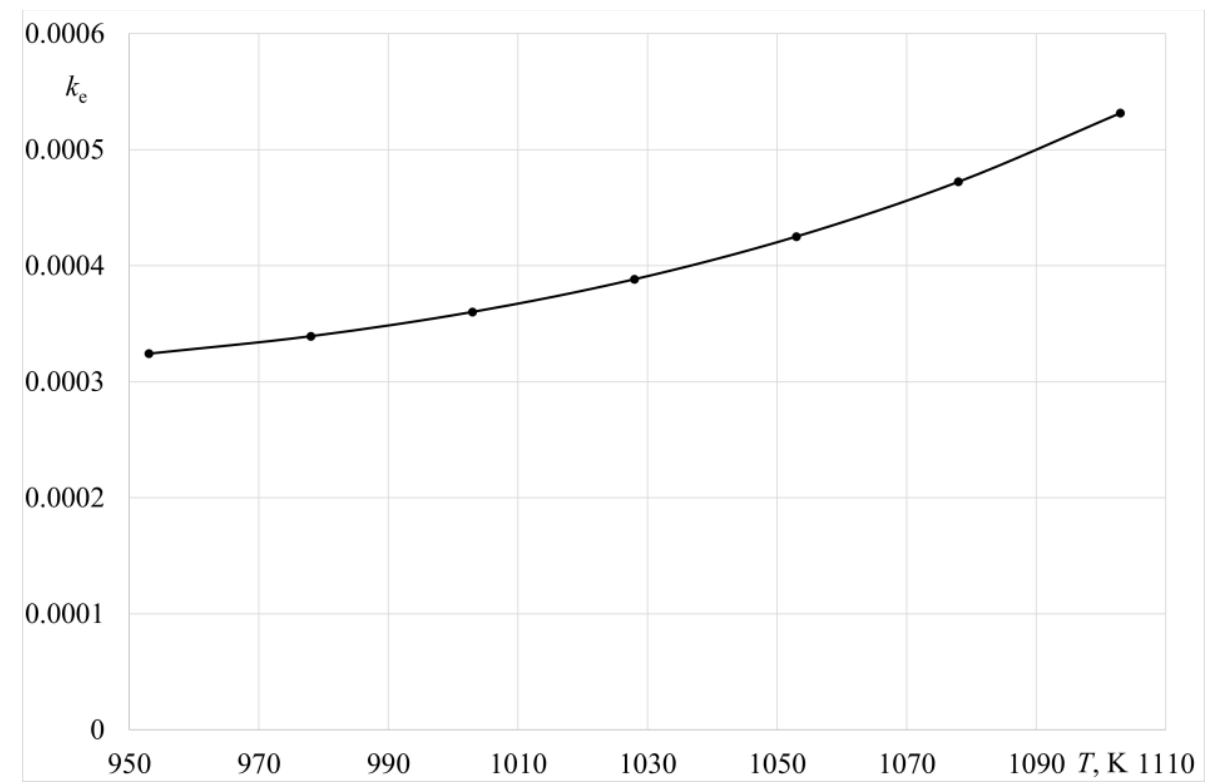

Figure 12. Effects of temperature on the coefficient $k^{e} \mathrm{Zn}$ value.

Figures 10 and 11 present an example of estimated transfer resistance, associated with a reaction occurring on the surface of the liquid alloy, as a fraction of the overall resistance of the zinc evaporation process for the experiments carried out at $1003 \mathrm{~K}$ and $1103 \mathrm{~K}$. The following equation was used:

$$
R^{e}=\frac{\left(\frac{1}{k^{e}}\right)}{\left(\frac{1}{k_{Z n}}\right)} \cdot 100 \%,
$$

Estimation of the resistance $R^{e}$ as a fraction of the overall process resistance, within the ranges of temperature and pressure applied in this research, showed that it changed from $1.5 \%$ to $28 \%$ for the experiments performed in the crucible induction furnace, and from $1.5 \%$ to $11 \%$ for the experiments carried out in the furnace with a cold crucible (only $953 \mathrm{~K}$ for this device).

Based on the analysis of the experiments' findings, it can be concluded that with operating pressures of $100 \mathrm{~Pa}$ to $1000 \mathrm{~Pa}$ in both melting devices, as well as the analysed temperature range, the process of zinc evaporation from liquid aluminium is determined by mass transfer in the gaseous phase. The overall resistance associated with mass transfer in the liquid phase $\left(R^{\beta l}\right)$ and with the reaction on the liquid metal surface $\left(R^{e}\right)$ was up to $22 \%$ of the overall process resistance (Figures 10 and 11 ). Pressure lowering to 10 Pa results in an increase in the total resistance $\left(R^{\beta l}+R^{e}\right)$ of up to $65 \%$ (Figures 10 and 11 ).

\subsection{Mass Transfer in the Gaseous Phase}

None of the known hydrodynamic models used to describe mass transfer in the gaseous phase enable precise estimation of the mass transfer coefficient $\beta^{g} \mathrm{Zn}$ for the measurement system applied in the research. Similarly, there are no criteria provided in the literature to determine properly this coefficient value.

Therefore, to describe the role of phenomena associated with mass transfer in the gaseous phase in the analysed zinc process, the overpressure ratio (OPR) was used according to the suggestion provided in [32]. This parameter is defined as a ratio of the sum 
of initial pressures of the bath components over the alloy to the pressure in the furnace working chamber.

$$
\mathrm{OPR}=\frac{\sum_{i=1}^{n} p_{i}}{p_{c h}}
$$

It is assumed that transport in the gaseous phase does not determine the rate of the analysed metal evaporation process under reduced pressure when the following condition is met:

$$
\text { OPR }>1 \text {, }
$$

To estimate the OPR coefficient for the analysed temperature range applied in the experiments, vapour pressures of all volatile components over liquid Al-Zn alloy were considered. The OPR values versus temperature are presented in Figure 13. The data suggest that the analysed process is not determined by mass transfer in the gaseous phase only for the pressure of $10 \mathrm{~Pa}(\mathrm{OPR}>1)$.

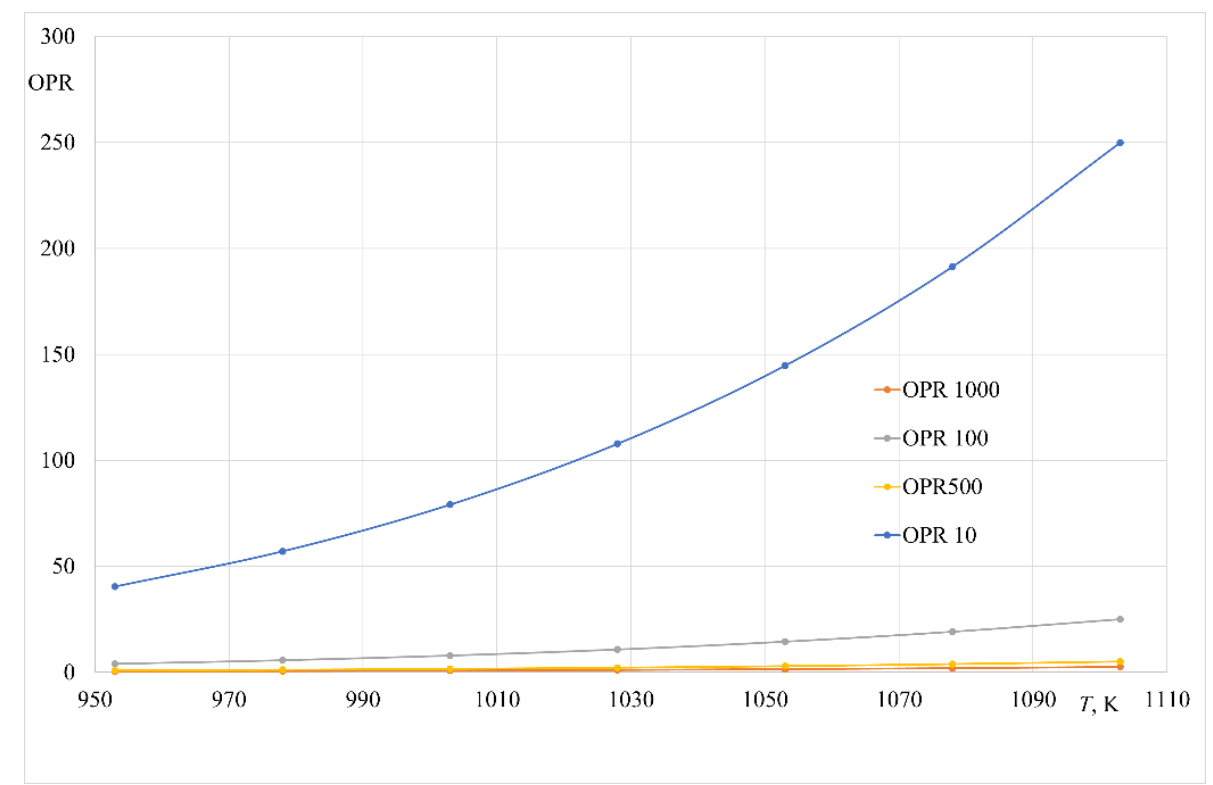

Figure 13. Change in the value of the OPR coefficient for different working pressures of the furnace.

\section{Conclusions}

As part of the above research, a kinetic analysis of zinc evaporation from aluminium during its smelting in the crucible induction furnace and the induction furnace with a cold crucible was carried out. The analysis involved the following procedures:

- Determination of the values of the overall mass transfer coefficient $k_{Z n}$ regarding the evaporating component;

- Estimation of the values of mass transfer coefficients in the liquid phase $\beta^{l}$ and the evaporation rate constant $k^{e}$;

- Determination of the stages defining the investigated process.

The research findings and their analysis led to the following conclusions:

1. For the experiments carried out in the crucible induction furnace, reduction in the operating pressure in the furnace from $1000 \mathrm{~Pa}$ to $10 \mathrm{~Pa}$, together with the increase in temperature from $953 \mathrm{~K}$ to $1103 \mathrm{~K}$, is accompanied by a decrease in zinc content in the alloy from 6 to $96 \%$, compared with the initial value. Simultaneously, the overall mass transfer coefficient $k_{Z n}$ increases from $5.15 \times 10^{-6}$ to $1.49 \times 10^{-4} \mathrm{~ms}^{-1}$.

2. For the experiments carried out in the furnace with a cold crucible $(T=953 \mathrm{~K})$, a reduction in the operating pressure in the furnace from $1000 \mathrm{~Pa}$ to $10 \mathrm{~Pa}$ resulted in a decrease in zinc content in the alloy from 18 to $80 \%$, compared with the initial value. 
Simultaneously, the overall mass transfer coefficient $k_{Z n}$ increases from $5.17 \times 10^{-6}$ to $3.34 \times 10^{-5} \mathrm{~ms}^{-1}$.

3. For comparison, the experiments carried out in the crucible induction furnace at $953 \mathrm{~K}$ showed a reduction in zinc content in the alloy from 6 to $50 \%$, which means that more intense zinc evaporation is seen in the furnace with a cold crucible. This effect is caused by a far larger evaporation surface (liquid metal surface) for this device (Table 4).

4. The rate of analysed zinc evaporation within $100 \mathrm{~Pa}$ to1000 $\mathrm{Pa}$ is controlled by the mass transfer rate in the gaseous phase. The overall resistance associated with mass transfer in the liquid phase $\left(R^{\beta l}\right)$ and with the reaction on the liquid metal surface $\left(R^{e}\right)$ was up to $22 \%$ of the overall process resistance for this pressure range.

5. For $10 \mathrm{~Pa}$, the overall resistance associated with mass transfer in the liquid phase $\left(R^{\beta l}\right)$ and with the reaction on the liquid metal surface $\left(R^{e}\right)$ constitutes nearly $70 \%$ of the overall process resistance.

Author Contributions: Conceptualisation, A.S. (Albert Smalcerz) and B.W.; methodology, B.W.; validation, A.S. (Albert Smalcerz), L.B. and B.W.; formal analysis, J.L.; investigation, B.W.; resources, L.B.; data curation, A.S. (Adrian Smagor); writing — original draft preparation, A.S. (Albert Smalcerz); writing—-review and editing, L.B.; visualisation, M.J.; supervision, J.L.; project administration, M.J.; funding acquisition, A.S. (Adrian Smagor). All authors have read and agreed to the published version of the manuscript.

Funding: This research was funded by the Silesian University of Technology, Grant No. 11/040/ BK_21/0023.

Institutional Review Board Statement: Not applicable.

Informed Consent Statement: Not applicable.

Data Availability Statement: Data sharing is not applicable to this article.

Conflicts of Interest: The authors declare no conflict of interest.

\section{References}

1. Wecki, B. Analysis of the Influence of the Contact Area Size between the Liquid Metal Phase and the Gas Phase on the Efficiency of the Metal Refining Process in Induction Crucible Furnaces. Ph.D. Dissertation, Silesian University of Technology, Gliwice, Poland, 2018.

2. Deng, H.; Dong, J.; Boi, F.; Saunders, T.; Hu, C.; Grasso, S. Magnetic Field Generated during Electric Current-Assisted Sintering: From Health and Safety Issues to Lorentz Force Effects. Metals 2020, 10, 1653. [CrossRef]

3. Smalcerz, A.; Przylucki, R. Electromagnetic Field Analysis of Inductor-Robot-Workpiece System. Metalurgija 2013, 52, $223-226$.

4. Niklewicz, M.; Smalcerz, A. Application of three-coil cylindrical inductor in induction heating of gears. Electr. Rev. 2010, 86, 333-335.

5. Niklewicz, M.; Smalcerz, A. Estimation of system geometry and inductor frequency importance in induction hardening process of gears. Electr. Rev. 2008, 84, 219-224.

6. Biesuz, M.; Saunders, T.; Ke, D.; Reece, J.M.; Hu, C.; Grasso, S. A review of electromagnetic processing of materials (EPM): Heating, sintering, joining and forming. J. Mater. Sci. Technol. 2021, 69, 239-272. [CrossRef]

7. Gombert, D.; Richardson, J.; Aloy, A.; Delbert, D. Cold-Crucible design parameters for next generation HLW melters. Waste Manag. 2002, 2, 24-28.

8. Vogt, M.; Bernier, F.; Mühlbauer, A.; Blum, M.; Jarczyk, G. Experimental investigation of temperature field and energy flows in induction furnace with cold crucible and a practical application of the results. In Proceedings of the International Conference Electromagnetic Processing of Materials EPM 2000, Nagoya, Japan, 3-6 April 2000.

9. Baake, E.; Nacke, B.; Bernier, F.; Vogt, M.; Mühlbauer, A.; Blum, M. Experimental and numerical investigations of the temperature field and melt flow in the induction furnace with cold crucible. In Proceedings of the International Symposium on Heating by Internal Sources HIS 2001, Padua, Italy, 12-14 September 2001.

10. Lavers, J.D.; Biringer, P.P.; Segsworth, R.S. Current distribution, forces and circulation in the coreless furnace. IEEE Trans. Ind. Appl. 1973, 4, 395-399. [CrossRef]

11. Bojarevics, V.; Djambazov, G.; Harding, R.; Pericleous, K.; Wickins, M. Investigation of the cold crucible melting, Process: Experimental and Numerical Study. Proc. Fifth Int. Pamir Conf. Fundam. Appl. MHD 2002, 2, II.77-II.82.

12. Delage, D.; Ernst, R.; Driole, J. Induction melting in a cold crucible. In Proceedings of the Symposium IUTAM, Cambridge, UK, 7-11 June 1982; p. 108. 
13. Gagnoud, A.; Etay, J.; Garnier, M. The levitation melting process using cold crucible technique. ISIJ Int. 1988, 28, 38. [CrossRef]

14. Guo, J.; Liu, Y.; Su, Y. Evaporation of multi-components in Ti-25Al-25Nb melt during induction skull melting process. Trans. Nonferrous Met. Soc. China 2002, 12, 587-591.

15. Olette, M. Physical Chemistry of Process Metallurgy; Part 2; St-Pierre, G.R., Ed.; Interscience: New York, NY, USA, 1961; pp. 1065-1087.

16. Plewa, J. Przykłady Obliczeń z Teorii Procesów Metalurgicznych; Wydawnictwo Politechniki Śląskiej: Gliwice, Poland, 1987.

17. Roine, A. HSC Chemistry ver. 6.1 Thermo-Chemical Database; Outotec Research Oy: Pori, Finland, 2007.

18. Ward, R.G. Evaporative losses during vacuum induction melting of steel. J. Iron Steel Inst. 1963, 1, 11-15.

19. Nash, P.M.; Steinemann, S.G. Density and Thermal Expansion of Molten Manganese. Iron. Nickel. Copper. Aluminium and Tin by Means of the Gamma-Ray Attenuation Technique. Phys. Chem. Liq. Int. J. 1995, 29, 43-58. [CrossRef]

20. Assael, M.; Kakosimos, K.; Banish, R. Reference Data for the Density and Viscosity of Liquid Aluminum and Liquid Iron. J. Phys. Chem. Ref. Data 2006, 35, 285-300. [CrossRef]

21. Yoshida, T.; Nagasaka, T.; Hino, M. Evaporation Rates of Zinc and Lead in Copper Melt under Reduce Pressure. J. Jpn. Inst. Met. 1999, 63, 167-173. [CrossRef]

22. Ma, Y.; Qui, K. Separation and recovery of zinc from copper-based alloy scraps under vacuum conditions. Vacuum 2014, 106, 5-10. [CrossRef]

23. Hino, M.; Wang, S.; Nagasaka, T.; Ban-Ya, S. Evaporation Rate of Zinc in Liquid lron. ISIJ Int. 1994, 34, 491-497. [CrossRef]

24. Wei, Q.; Yang, B.; Li, Y.; Dai, Y. Zinc Removing from Aluminum alloy by Vacuum Distillation. Adv. Mater. Res. 2012, $402,303-306$. [CrossRef]

25. Machlin, E.S. Kinetics of Vacuum Induction Refining-Theory. Trans. Am. Inst. Min. Metall. Eng. 1960, 218, $314-326$.

26. Przyłucki, R.; Golak, S.; Oleksiak, B.; Blacha, L. Influence of an induction furnace's electric parameters on mass transfer velocity in the liquid phase. Metalurgija 2012, 1, 67-70.

27. Blacha, L.; Przyłucki, R.; Golak, S.; Oleksiak, B. Influence of the geometry of the arrangement inductor-Crucible to the velocity of the transport of mass in the liquid metallic phase mixed inductive. Arch. Civ. Mech. Eng. 2011, 11, 171-179.

28. Blacha, L.; Golak, S.; Jakovics, S.; Tucs, A. Kinetic Analysis of Aluminum Evaporation from Ti-6Al-7Nb. Arch. Metall. Mater. 2014, 59, 275-279. [CrossRef]

29. Blacha, L.; Fornalczyk, A.; Przyłucki, R.; Golak, S. Kinetics of the evaporation process of the volatile component in induction stirred melts. In Proceedings of the 2nd International Conference of Simulation and Modelling of Metallurgical Processes in Steelmaking, Steelsim 2007, Graz, Austria, 12-14 September 2007; Ludwig, A., Ed.; ASMET: Leoben, Austria, 2007 ; pp. $389-395$.

30. Aldalur, E.; Suárez, A.; Veiga, F. Metal transfer modes for Wire Arc Additive Manufacturing Al-Mg alloys: Influence of heat input in microstructure and porosity. J. Mater. Process. Technol. 2021, 297, 117271. [CrossRef]

31. Du, Y.; Chang, Y.; Huang, B.; Gong, W.; Jin, Z. Diffusion coefficients of some solutes in fcc and liquid Al: Critical evaluation and correlation. Mater. Sci. Eng. A 2003, 363, 140-151. [CrossRef]

32. Harris, R.; Davenport, W.G. Vacuum distillation of liquid metals. Metall. Trans. B 1982, 13, 581-588. [CrossRef] 